\title{
UC-41
}

Issued: September 1985

\section{Radiation Monitor for Surveillance of Moving Vehicles}

$\mathrm{LA}--1040 \therefore-\mathrm{MS}$

DE86 003287

Robert F. Dvorak

\section{DISCLAIMER}

\begin{abstract}
This report was prepared as an account of work smang
Government. Neither the as account of work

employees, makes any warranty, express or implied nor any agency theref the United States
bility for the accuraciter process disclosed, acy, completeness, or urefulied, or assumes any thereof, nor any of their ence herein to any represents that its use would of any information, liability or responsimanufacturer, or otherwic commercial product, prot infringe privately ownedus, product, or mendation, or favoring by does not necessarily conss, or service by trade named rights. Referand opinions of auth by the United States Gonstitute or imply its endame, trademark United States Government expressed herein do novernment or any agency thersement, recomagency thereof.
\end{abstract}




\title{
RADIATION MONITOR FOR SURVEILLANCE \\ OF MOVING VEHICLES
}

by

Robert F. Dvorak

\begin{abstract}
A radiation monitor has been developed that will scan each vehicle leaving the clinton P. Anderson Los Alamos Meson Physics Facility site. If an increase in radiation level is sensed, an alarm light and a Klaxon horn are activated, inviting the driver to return to the Health Physics office for check. A photograph showirg the vehicle icense number is also taken. A radiation source that doubles the detector count rate when stationary will cause an alarm at vehicle speeds up to about $24 \mathrm{~km} / \mathrm{h}$ ( $15 \mathrm{mph})$. The technique used to prevent false alarms because of radiations from nearby buildings or from plumes of low-level radioactive gas is described.
\end{abstract}

\section{INTRODUCTION}

The Los Alamos Meson Physics Facility (LAMPF) is built around an $800-\mathrm{MeV}$ proton linear accelerator. Average beam current is currently 500 to $1000 \mu \mathrm{A}$. Under these operating parameters, materials associated with the primary beam line are quickly and sometimes intensely activated, and materials along secondary beam lines may become significantly radioactive. 
One consequence of this situation is that there is a resulting wealth of radioactive objects ranging from nuts, bolts, and shins to TV cameras, transducers, and power supplies that could be intentionally or unintentionally transported from the LAMPF site. Personnel with concaminated clothing or shoes, radioactive materials inadvertently mixed with nonradioactive waste, and other norinaity monitored situations can escape altention in a large accelerator facility and are a constant source of concern. The location of the facility is such that access is a lmost exclusively by vehicles of one kind or another, and there is unly one access road to the site. Therefore, it was Felt that an appropriate second line of defense against unauthorized transport of radioactive materials would be a vehicle monitor at an appropriate location on the access road.

\section{INITIAL DESIGN CONGIDERATIONS}

The obvious location for the monitor was near the entrance gate guard station. The station was manned on a 24-hour basts, had space for an electronics package and signal lights, and had an adjacent open area in which a vehicle could turn around.

Since the range of vehicle heights and widths varies enormously, from semilrailers and l00-lon cranes to Volkswagens and bicycles, it was felt that the most practical monitoring point to locate the delector was in the road where it could scan the passing vehicles from the bottom.

Accordingly, the detector package was placed in an aluminum-covered manhole located about $90 \mathrm{ft}$ before the guard 
station in the extt lane. The electronics package was mounted in the guard station with connection to the detector by buried conduit. An alarm light and a klaxon horn were mounted on the roof along with instructions to stop at the guard station on alarm. Flg. I shows the guard station with attendant signs, light, and Klaxon horn.

\section{SUBSEQUENT DESIGN CHANGES}

Just prior to installation of the system, the guards were removed from this location. This necessitated, hesides changing the signs, transferring the alarm signal and alarm reset by telephone line to the Health Physics Office over $1 / 2$ mile away. Since vehicle exit speeds immediately increased from about $15 \mathrm{mph}$ to over $45 \mathrm{mph}$, a speed-1imiting depression, $3 \mathrm{ft}$ wide and about 3 in. deep, was cut inlo the road. As additional incentive to return for monitoring after an alarm, a box containing a Polaroid Sx-70 camera with telephoto lens and flash was located so as to photograph the vehicle and, in particular, the license plate. Fig. 2 shows the monitoring point.

Los Alamos is credited with the second highest lightning frequency in the US. The tuff underlying the installation has very poor grounding qualities, and lightning strikes within, roughly, a five-mile radius usually result in a false alarm. To make the problem more serious, during the rainy season, the storms occur primarily at noon and late afternoon, periods of heavy traffic movement.

To reduce the effect, the manhole cover and sides and the 
lead detector shielding were carefully grounded to the electrical conduit, which, in turn, was connected to the guard-station walls and the electronics package. A single-channel analyzer was added to screen out the large pulses characteristic of the lightning event. Finally, a vehicle-presence loop was placed in the road, and the alarm circuit was modified to include vehicle presence as an alarm requirement.

The next problem appeared as accelerator output increased. When the plume of radioactive gas (air) from the accelerator stack is over the guaru station, increases of background radiation by as much as a factor of lo are seen. This condition can persist for periods up to an hour, and should a vehicle exit durlng this period, an alarm will be triggered. The latest system change was to locate an unshielded detector in the guard station to determine hackground radiation. The output of the vehicle monitor is then referenced to this background level of radiation in determining an alarm condition.

\section{DETECTOR}

The detectors are integral line units with a 5-in. diameter by l-in.-thick sodium iodide (Tl) crystal on a 5-in. photomultiplier tube. Resolutiun has not been measured since it is not particularly important in this appliraton. Optimum crystal thickness has not heen determined, although in our environment, the 1-in.-thick deteclor has better signal-to-background ratio than a 2-in.-thick detector. A preamplifier of gain 6 is located at the tube base to drive the signal cable. 
A waterproof plastic case approximately 16 in. $x 16$ in. $x 18$ 1n. high was selected to protect the detector and is shown in Fig. 3. The case was initially filled with polystyrene foam insulation and a space hollowed out for the photomultiplier-preamp assembly so that a miniumum of $31 \mathrm{in}$. of insulation protects the photomultiplier from thermal stress as shown in Fig. 4. The detector box is located in a 24-1n.-diameter manhole, as close to the road level as possible, with a l-in.-thick sheet of beaded polystyrene positioned between the box and the aluminum manhole cover to reduce thermal coupling. Lead sheets are placed around and under the box to achieve about $1 / 21 \mathrm{n}$. of shielding from the surrounding soll that reduces background by approximately $30 \%$.

\section{ELECTRONICS}

With the exception of the alarm modules, the electronic components are conventional. A schematic is shown in Fig. 5. To minimize notse problems, the PM tube is operated at relatively high voltage and, correspondingly, the pulse amplifier is set at a relatively low gain. The single-channel analyzer module is used with a window between $75 \mathrm{keV}$ and $1.5 \mathrm{MeV}$. These settings are not necessarily optimum, but clearly an upper level cutoff is necessary to reduce the interference from 11 ghtning-generated notse.

The outputs of the two count-rate meters are scaled to equal voltage levels, and an adjustable increment is added to the background signal to allow for statistical fuctuations. A monitor signal in excess of the conditioned background signal initiates 
an alarm. If a vehicle is present, as indicated by the loop vehicle detector, the alarm controller is activated, causing the warning light to be turned on, the klaxon horn to be sounded, and a photo to be taken. Alarm is also sounded in the Health Phystcs offices from which point appropriate action is initiated. Fig. 6 shows one of lhe remote alarm boxes. Alarm reset and a partial system disable can be accomplished from the remote office locations.

CAMERA

The camera unit is shown in Fig. 7. The upper segtion (see Fig. 8) holds the control unit, the sX-70 camera with telephoto lens and the flash. This section is insulated with l in. of polystyrene foam and temperature is stabilized by $a$ thermostatically controlled heating tape.

One problem with the flash unit is that it draws part af its power from the film-pack battery, and in less than 24 hours of continuous operation, drains the battery. To prevent this, the flash cable was cut and relay contacts were interposed. On receiving an alarm signal, all flash cable contacts are closed and the shutter is triggered.

Later, the flash batteries were replaced by a dumm plug, and the power source is now a 6-volt storage battery in the lower compartment (Fig. 9). This battery also supplies power for the previously mentioned relays. The lower compartment also houses a 5-amp charger controlied by a clock timer. 


\section{SENS I T IVITY}

The system sensitivity is difficult to describe since it depends on the path of the source through the detector cone-of-sensitivity, the amount of attenuation by interposed shielding materials, and the speed of the vehicle.

The rule-of-thumb in the present system is that if a pasing source increases the detector counting rate to twice the background level, then the system will alarm. A $12-\mu \mathrm{Ci}{ }^{60} \mathrm{Co}$ source placed on the floor of a pickup truck is used to test the system, and will generate an alarm at speeds up to about $17 \mathrm{mph}$.

\section{OPERATION STATISTICS}

In the past 24 months there have been 586 alarms, an average of about one per day. Of these alarms, $90.8 \%$ were anticipated, i.e., the shipment had been surveyed or otherwise cleared, and $9.2 \%$ required further action. Of the latter, $3.4 \%$ either returned to be checked or wated at the gate and called for a check, and $1.2 \%$ ignored the alarms and were traced from the photograph and other evidence. The remaining $4.6 \%$ were false alarms, the most common causes being loss of power, the radioactive gas plume, and telephone company work on the patch panels.

\section{OPERATING EXPERIENCE}

Special situations have been accommodated with little difficulty. Cancer patients undergoing treatment at the Pion Facility frequently have residual induced activity so the receptionist notifies Health Physics when they are departing, and the trans- 
porter, whether private vehicle or Laboratory taxi, is instructed not to stop or return. Employees with diagnostic amounts of radioisotopes are instructed to call Health Physics prior to leaving the site and, similarly, disregard the a $1 \mathrm{arm}$.

The unattended system has worked surprisingly well. The vast majority of vehicles transporting radioactive materials either report to Health Physics before leaving the site or return voluntarily for monitoring when the alarm is triggered. Since we have demonstrated our ability to track down, within a few hours, those vehicles that trigger the alarm and do not return for monitoring, cooperation has been especially good. 


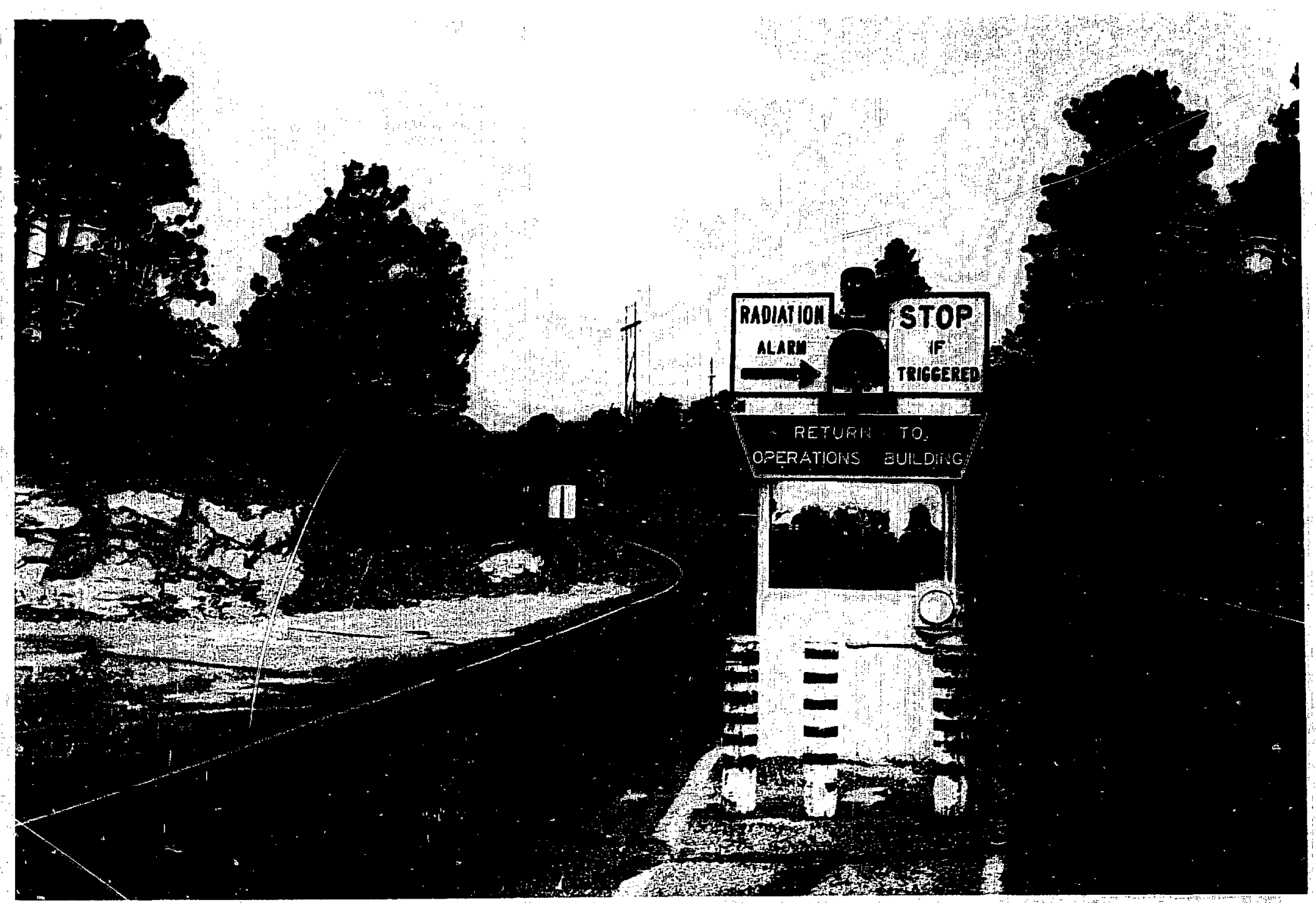

Figure 1. The guard station with alarm light and Klaxon. The system electronics are mounted inside the station. 


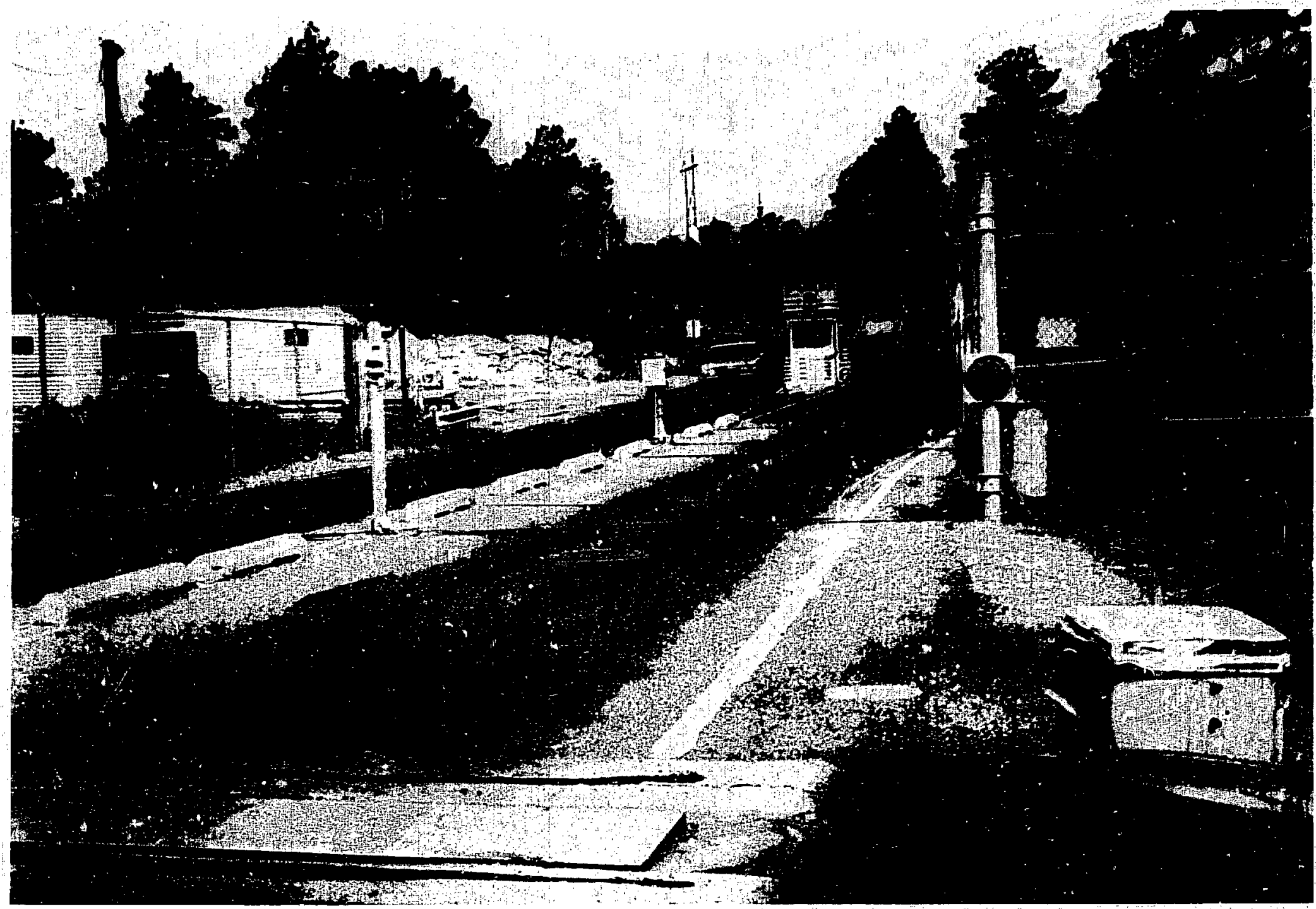

Figure 2. The monitoring point. In the foreground left is the speed depression and in the foreground right the camera box. The covered manhole for the detector is at the center. 


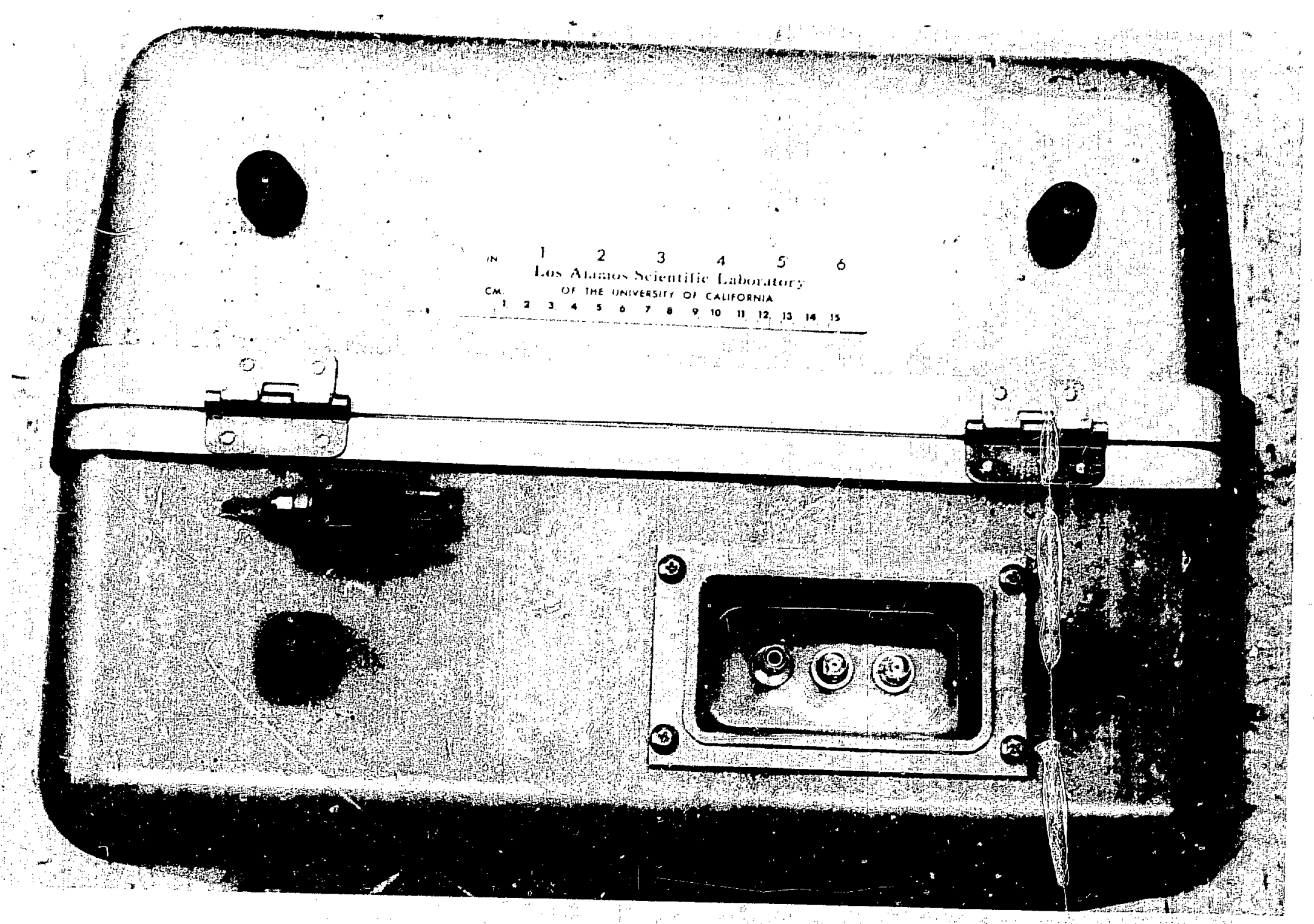

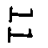

Figure 3. The detector case, showing power and signal connectors. 


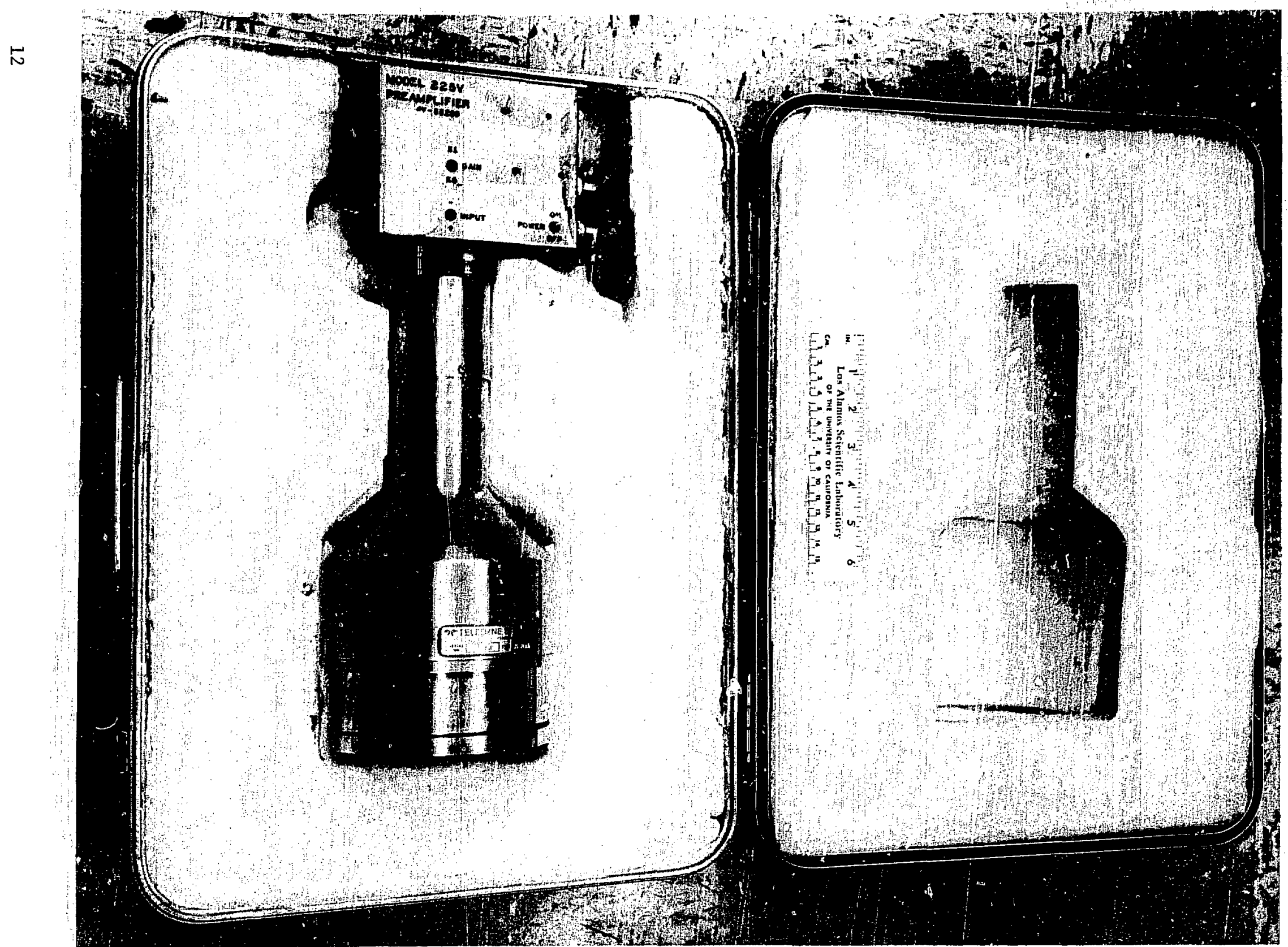

Figure 4. The detector case interior showing the photomultiplier and preamplifier. 


\section{LOCAL BACKGROUND}
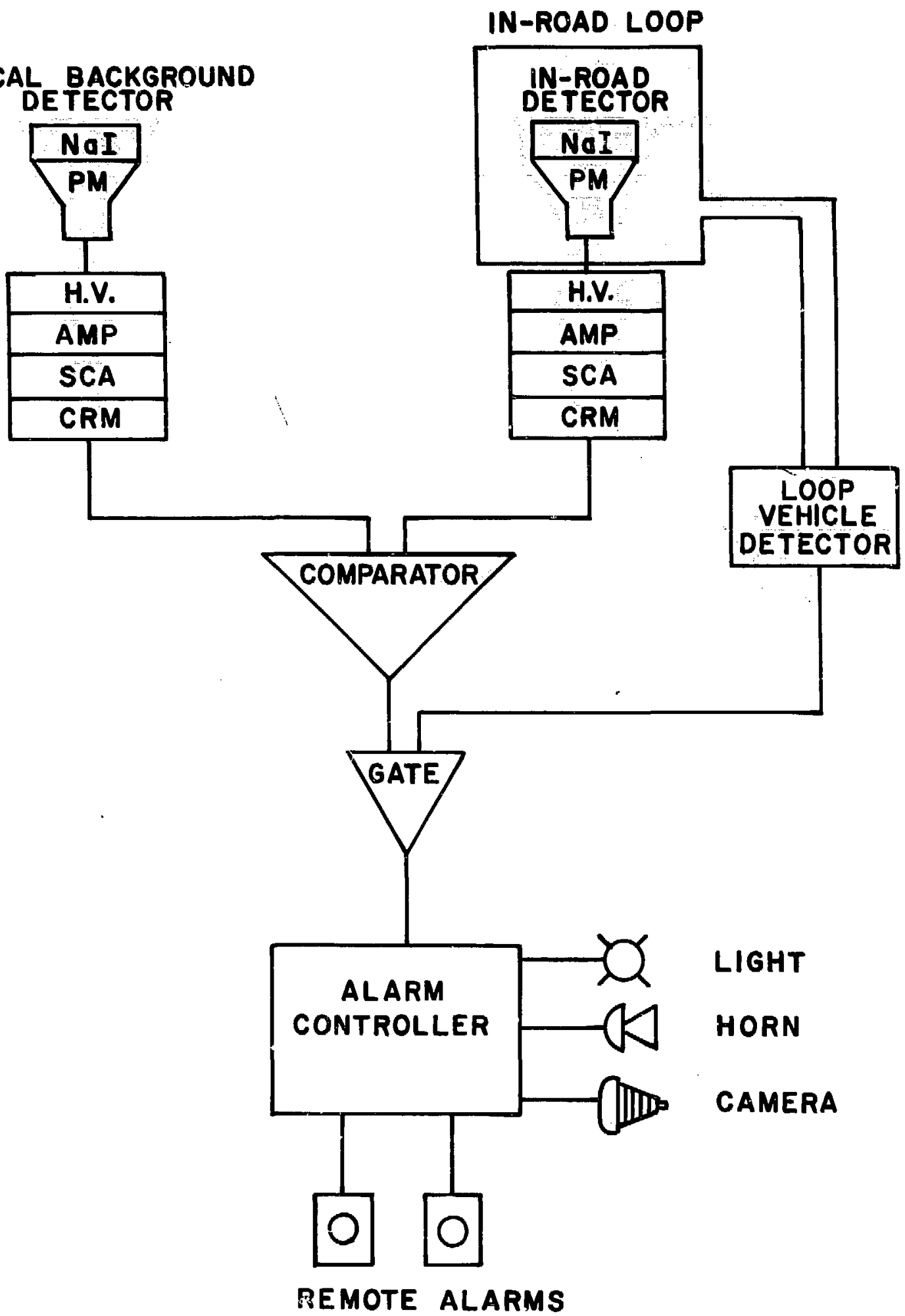

Figure 5. Schematic of monitoring system. 


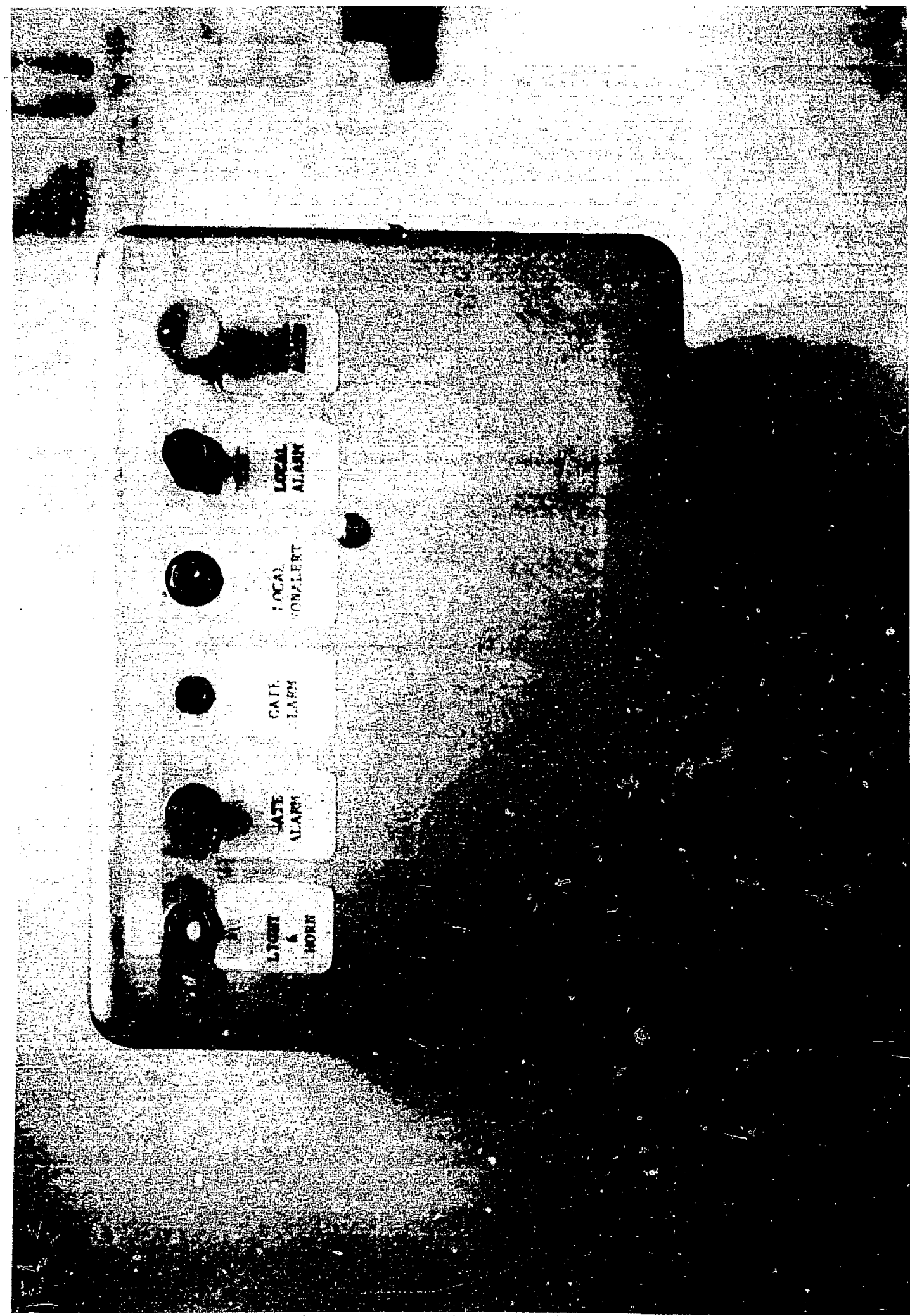




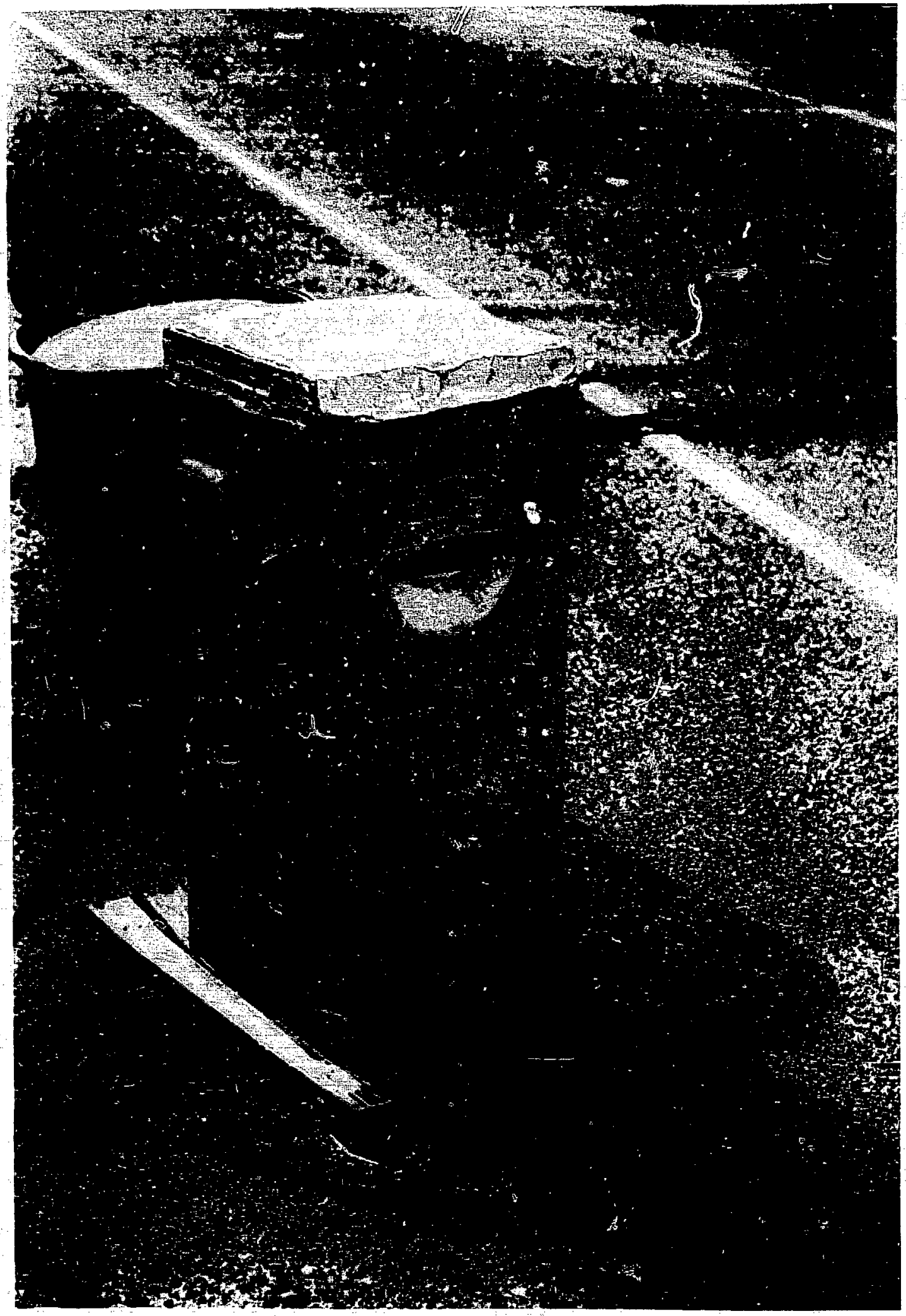

Figure 7. Camera unit. 


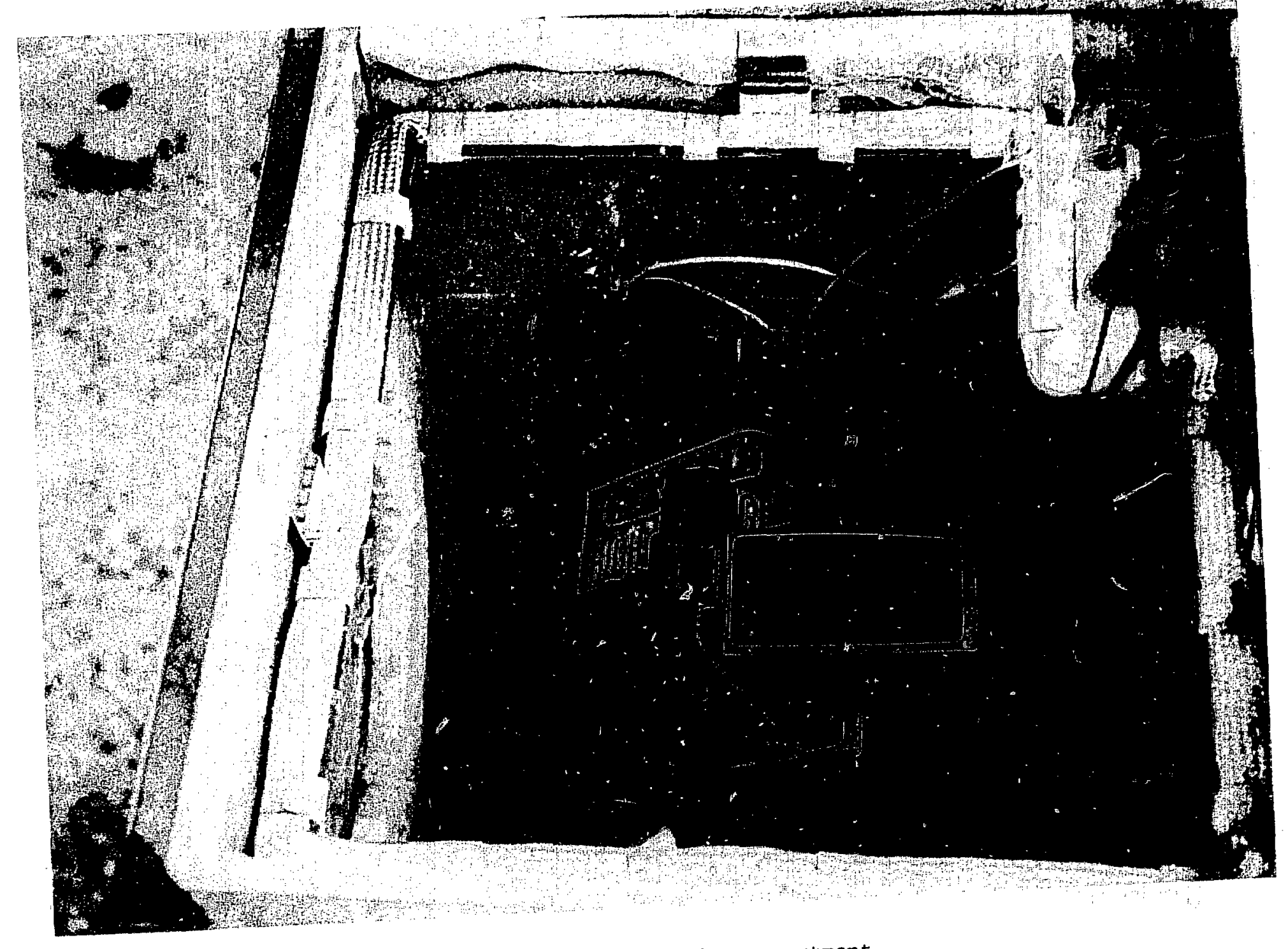

Figure 8. Upper camera unit compartment. 

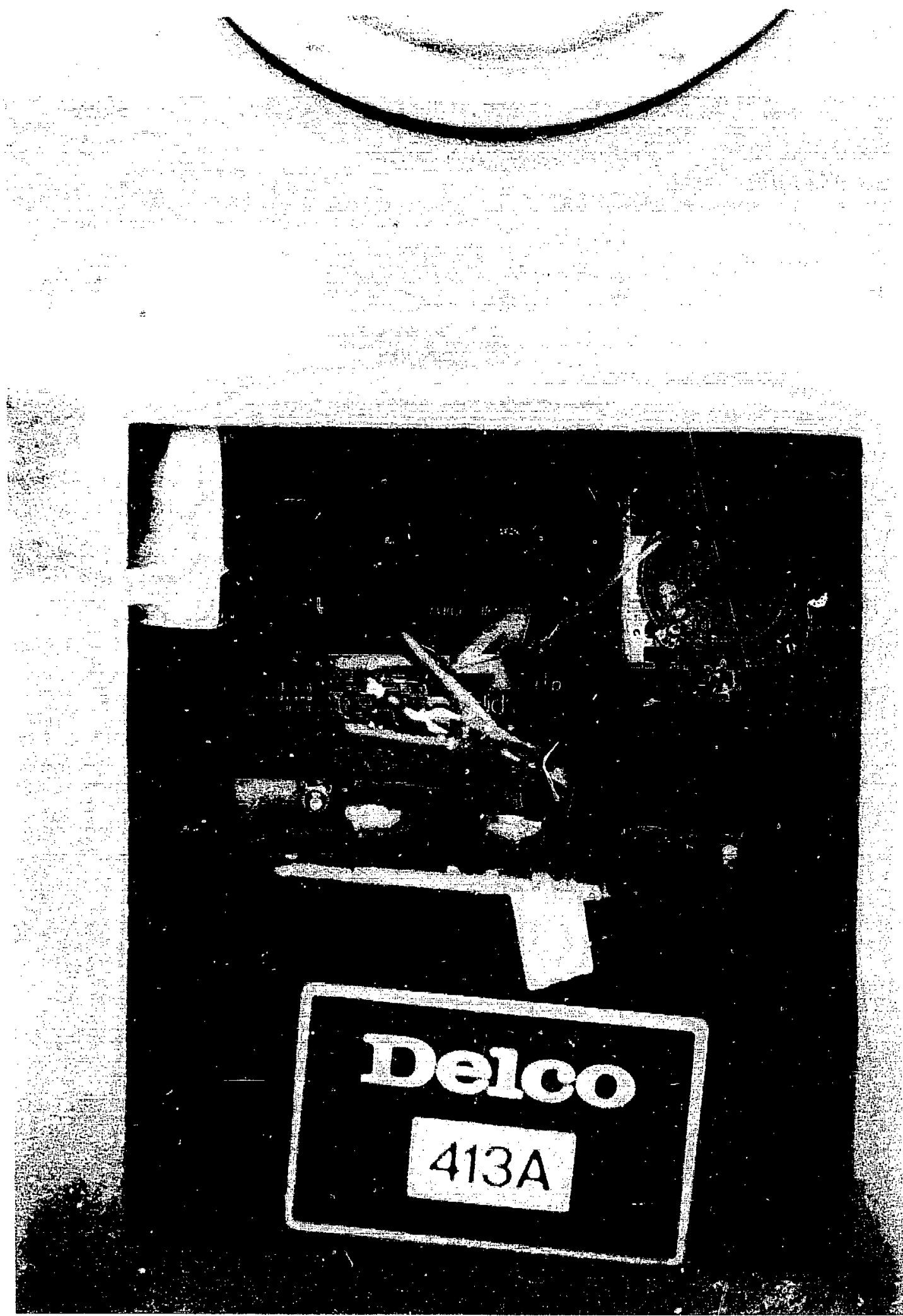

Figure 9. Lower camera unit compartment. 